\title{
OPTIMASI PROPILENGLIKOL DALAM SEDIAAN SIRUP OBAT BATUK EKSTRAK RIMPANG JAHE
}

\author{
N. P. A. I. Artania*, I K. G. G. G. Harta, G. W. A. P. Pratama, N. P. A. S. Ayu, \\ I. G. A. P. Sukmarani dan C. I. S. Arisanti \\ Program Studi Farmasi, Fakultas Matematika dan Ilmu Pengetahuan Alam, Universitas Udayana \\ Bukit Jimbaran, Badung, Bali, Indonesia \\ *Email: ayuintenartania@gmail.com
}

\begin{abstract}
ABSTRAK
Rimpang jahe (Zingiber officinale) memiliki efek farmakologi sebagai antitusif yang telah dibuktikan secara empiris dan melalui uji aktivitas secara in vivo. Penggunaan jahe secara langsung memiliki rasa pedas dan getir sehingga tidak begitu disukai. Berdasarkan hal tersebut maka perlu diformulasikan ke dalam sediaan sirup yang telah memenuhi uji kestabilan fisik untuk memperoleh formula terbaik. Pada penelitian ini, ekstrak air rimpang jahe yang telah terstandar dan telah dilakukan skrining diformulasikan menjadi sediaan sirup. Formulasi dilakukan dengan optimasi jumlah propilen glikol yaitu 15,20 , dan $25 \%$ sebagai kosolven dan anticaplocking terhadap sediaan sirup. Hasil yang diperoleh adalah konsentrasi propilenglikol dalam sediaan sirup ekstrak rimpang jahe berpengaruh terhadap stabilitas fisik sediaan. Tiga formula yang dikerjakan belum memenuhi persyaratan uji kestabilan fisik, namun formula 3 dengan 25\% propilen glikol merupakan formula terbaik dari sirup rimpang jahe.
\end{abstract}

Kata kunci: Antitusif, Rimpang jahe (Zingiber officinale), Sirup, Propilenglikol, Viskositas

\section{ABSTRACT}

Ginger (Zingiber officinale) has a pharmacological effect to be an antitussive which has been proven empirically and through in vivo activity testing. The use of ginger directly has a spicy and bitter taste, so it is not very popular. Based on this, it is necessary to formulate it into syrup preparation which has met the physical stability test to obtain the best formula. In this study, ginger rhizome water extract that had been standardized and screened was formulated into syrup preparations. The formulation was carried out by optimizing the amount of propylene glycol as co-solvents and anti-cap locking which was 15, 20, and $25 \%$ of syrup preparation. The results showed that the concentration of propylene glycol in ginger rhizome extract syrup preparation affected the physical stability of the preparation. The three formulas obtained have not met the physical stability tests $(\mathrm{pH}$ and viscosity), but formula 3 with $25 \%$ of propylene glycol was the optimum formula of ginger rhizome syrup.

Keywords: Antitussives, Ginger (Zingiber officinale), Syrup, Propylenglycol, Viscosity

\section{PENDAHULUAN}

Batuk merupakan upaya pertahanan paru terhadap rangsangan dan refleks fisiologis untuk melindungi paru dari trauma mekanik, kimia dan suhu, umumnya disebabkan karenakebiasaan yang kurang baik seperti merokok, paparan asap rokok, dan paparan polusi lingkungan (Pavort dkk.., 2008).Seringkali batuk menjadi gangguan terhadap aktivitas manusia sehingga perlu dilakukan penanganan yang tepat terhadap batuk. Salah satu upaya preventif yang dapat dilakukan adalah dengan pengobatan herbal. Di Bali sendiri dikenal dengan pengobatan herbal berdasarkan lontar usada. Salah satu tanaman yang digunakan dalam pengobatan maupun pencegahan batuk adalah jahe. Rimpang jahe mengandung polisakarida yang berupa kompleks alfa-glucan dengan poligalakturonan yang memiliki efek farmakologi sebagai antitusif (Bera et al., 2016). Berdasarkan efek farmakologi dari jahe tersebut maka dibuatlah sediaan sirup yang dapat menutupi rasa pedas jahe sehingga dapat dikonsumsi dengan lebih mudah. Formulasi yang diajukan dilakukan optimasi konsentrasi 
propilenglikol untuk mengetahui konsentrasi optimal propilenglikol sebagai kosolven dan anti-caplocking pada sediaan sirup.

\section{MATERI DAN METODE}

\section{Bahan}

Bahan uji yang digunakan adalah serbuk rimpang jahe, asam sitrat anhidrat, metil dan propil paraben, gliserin, propilenglikol, sukrosa, perppermint oil, dan akuades.

\section{Alat}

Alat yang digunakan meliputi timbangan analitik, blender,oven, pipet tetes, ViscometerBrookfield DV-E, pH-meter digital, Hot plate, alat uji kadar abu, penangas air, botol kaca gelap, kertas perkamen, spatula, cawan porselen, kertas saring, mikroskop, batang pengaduk, alat-alat gelas, bejana maserasi, ayakan no 60, mortar, stamper, sudip, piknometer, spuit.

\section{Cara Kerja}

\section{Standarisasi simplisia}

Standarisasi serbuk simplisia rimpang jahe (Tabel 1) yang dilakukan sebelum dilakukan ekstraksi guna mengetahui serbuk sebagai bahan dasar sudah memenuhi kriteria atau parameter yang ditetapkan sesuai dengan Farmakope Herbal Indonesia.

Tabel 1. Parameter standarisasi simplisia

\begin{tabular}{ll}
\hline \multicolumn{1}{c}{ Standarisasi } & \multicolumn{1}{c}{ Persyaratan } \\
\hline Susut pengeringan & Tidak lebih dari 10\% \\
Abu total & Tidak lebih dari 4,2\% \\
Abu tidak larut asam & Tidak lebih dari 3,2\% \\
Sari larut air & Tidak kurang dari 15,8\% \\
Sari larut etanol & Tidak kurang dari 5,7\% \\
\hline \multicolumn{2}{l}{ Sumber: Departemen } \\
2008.
\end{tabular}

\section{Ekstraksi serbuk simplisia}

Serbuk rimpang jahe diekstraksi menggunakan akuades dengan perbandingan bahan dan pelarut 25:1000 (b/v). Proses ekstraksi dilakukan selama 1 jam dengan menggunakan pemanasan suhu $100{ }^{\circ} \mathrm{C}$. Ekstrak yang diperoleh kemudian disaring dengan menggunakan corong pisah dan kertas saring. Filtrat yang diperoleh kemudian dievaporasi pada suhu $75{ }^{\circ} \mathrm{C}$ dalam oven untuk menghilangkan pelarut hingga diperoleh maserat kental (Pendit, dkk., 2016).

\section{Standarisasi Ekstrak}

Standarisasi ekstrak aqueus rimpang jahe dilakukan untuk menjamin kualitas ekstrak yang diperoleh. Oleh sebab itu sangat penting dilakukan sebelum ekstrak diolah menjadi suatu sediaan. Adapunhasil yang diperoleh dari standarisasi ekstrak dapat dilihat pada Tabel 2.

Tabel 2. Parameter standarisasi ekstrak

\begin{tabular}{ll}
\hline \multicolumn{1}{c}{ Standarisasi } & Persyaratan \\
\hline Kadar air & Tidak lebih dari $10 \%$ \\
Abu total & Tidak lebih dari $7,6 \%$ \\
Abu tidak larut asam & Tidak lebih dari $1,9 \%$ \\
\hline
\end{tabular}

Sumber: Departemen Kesehatan Republik Indonesia, 2008.

\section{Skrining Fitokimia Ekstrak}

Skrining fitokimia yang dilakukan terhadap ekstrak aqueus rimpang jahe meliputi uji tanin, uji triterpenoid dan steroid, uji flavonoid, dan uji saponin (Depkes RI, 2008).

\section{Optimasi Formulasi}

Tabel 3. Formulasi sirup ekstrak jahe

\begin{tabular}{lccc}
\hline \multicolumn{1}{c}{ Bahan } & $\begin{array}{c}\text { Formula } \\
\mathbf{1}\end{array}$ & $\begin{array}{c}\text { Formula } \\
\mathbf{2}\end{array}$ & $\begin{array}{c}\text { Formula } \\
\mathbf{3}\end{array}$ \\
\hline $\begin{array}{l}\text { Ekstrak } \\
\text { kental } \\
\text { rimpang jahe }\end{array}$ & $1,33 \%$ & $1,33 \%$ & $1,33 \%$ \\
$\begin{array}{l}\text { Sukrosa } \\
\text { Asam sitrat }\end{array}$ & $67 \%$ & $67 \%$ & $67 \%$ \\
$\begin{array}{l}\text { anhidrat } \\
\text { Metil paraben }\end{array}$ & $0,18 \%$ & $2 \%$ & $2 \%$ \\
$\begin{array}{l}\text { Propil } \\
\text { paraben }\end{array}$ & $0,02 \%$ & $0,18 \%$ & $0,18 \%$ \\
$\begin{array}{l}\text { Gliserin } \\
\text { Propilenglikol }\end{array}$ & $3 \%$ & $3 \%$ & $0,02 \%$ \\
$\begin{array}{l}\text { Peppermint } \\
\text { oil }\end{array}$ & $\begin{array}{c}0,05 \% \\
\text { Aq }\end{array}$ & $20 \%$ & $25 \%$ \\
Aquadest & $\begin{array}{c}\mathrm{Ad} 100 \\
\mathrm{~mL}\end{array}$ & $\begin{array}{c}\mathrm{Ad} 100 \\
\mathrm{~mL}\end{array}$ & $\begin{array}{c}\mathrm{Ad} 100 \\
\mathrm{~mL}\end{array}$ \\
\hline
\end{tabular}

Sirupus simpleks dibuat terlebih dahulu dalam wadah terpisah. Ekstrak kental jahe dicampur dengan propilenglikol sambil digerus di dalam mortir (Campuran A). Di dalam mortir terpisah digerus asam sitrat anhidrat, metil paraben, dan propil paraben hingga homogen. Ditambahkan gliserin dan peppermint oil kemudian digerus kembali hingga homogen (campuran B). Campuran A dan campuran B kemudian dimasukkan ke dalam gelas beaker dan diletakkan diatas penangas air kemudian diaduk hingga homogen. Ditambahkan sirupus simplex 
ke dalam campuran bahan yang kemudian diaduk hingga diperoleh sirupus simplex yang homogen. Campuran dimasukkan ke dalam botol kaca coklat $100 \mathrm{~mL}$ yang sebelumnya telah ditara kemudian ditambah dengan akuades hingga tanda batas. Digojog hingga homogen.

\section{Evaluasi}

Evaluasi yang dilakukan untuk sediaan nanoemulsi meliputi uji organoleptis, uji keasaman $(\mathrm{pH})$, uji homogenitas, uji volume terpindahkan, dan uji viskositas.

\section{HASIL DAN PEMBAHASAN}

Ekstraksi serbuk simplisia menghasilkan rendemen yang cukup tinggi yaitu sebesar $13,184 \%$. Rendemen sangat mempengaruhi perolehan senyawa yang terkandung dalam ekstrak. Standarisasi simplisia dan ekstrak yang dihasilkan dapat dikatakan memiliki hasil yang kurang baik. Ekstrak yang diperoleh adalah ekstrak kering berwarna coklat kekuningan memiliki bau khas jahe dapat dilihat pada Gambar 1. Hasil standarisasi ekstrak yang diperoleh dapat dilihat pada Tabel 4. Parameter yang memenuhi persyaratan dari standarisasi simplisia dan ekstrak rimpang jahe hanya kadar abu total simplisia dan ekstrak. Hal tersebut dapat disebabkan oleh pengunaan serbuk simplisia yang tidak layak. Serbuk simplisia yang diperoleh tidak dilakukan sendiri melainkan membeli secara online melalui aplikasi jual beli online.

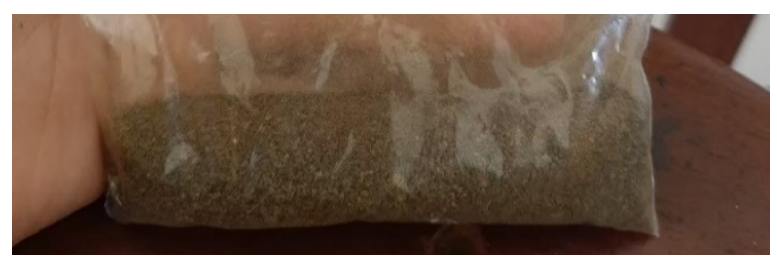

Gambar 1. Ekstrak kering rimpang jahe

Tabel 4. Hasil standarsasi simplisia dan ekstrak rimpang jahe

\begin{tabular}{ccccccc}
\hline No & \multicolumn{1}{c}{ Sampel } & $\begin{array}{c}\text { Kadar abu } \\
\text { total }\end{array}$ & $\begin{array}{c}\text { Kadar abu tidak } \\
\text { larut asam }\end{array}$ & $\begin{array}{c}\text { Sari larut } \\
\text { air }\end{array}$ & $\begin{array}{c}\text { Sari larut } \\
\text { etanol }\end{array}$ & $\begin{array}{c}\text { Kadar } \\
\text { air }\end{array}$ \\
\hline 1 & Simplisia & $4,08 \% \mathrm{~b} / \mathrm{b}$ & - & $9,05 \% \mathrm{~b} / \mathrm{b}$ & $2,281 \% \mathrm{~b} / \mathrm{b}$ & - \\
\hline 2 & Ekstrak & $6,7535 \% \mathrm{~b} / \mathrm{b}$ & $2,34 \% \mathrm{~b} / \mathrm{b}$ & - & - & $11,99 \%$ \\
\hline
\end{tabular}

Uji fitokimia terhadap ekstrak kering bertujuan untuk mengetahui golongan senyawa yang terkandung di dalamnya. Analisis tahap awal ini merupakan analisis secara kualitatif. Hasil yang diperoleh pada uji fitokimia dapat dilihat pada Tabel 5.

Tabel 5. Hasil Skrining fitokimia ekstrak rimpang jahe

\begin{tabular}{clc}
\hline No & Golongan Senyewa Fitokimia & Hasil \\
\hline 1 & Tanin & - \\
\hline 2 & Triterpenoid dan steroid & + \\
\hline 3 & Flavonoid & + \\
\hline 4 & Saponin & - \\
\hline
\end{tabular}

Ket:(-) tidak mengandung senyawa yang diinginkan,

(+) mengandung senyawa yang diinginkan.

Deteksi senyawa polisakarida dalam sampel simplisia dilakukan dengan penambahan kloralhidrat yang diamati dibawah mikroskop dengan perbesaran 10x. hasil yang diperoleh dapat dilihat pada Gambar 2.

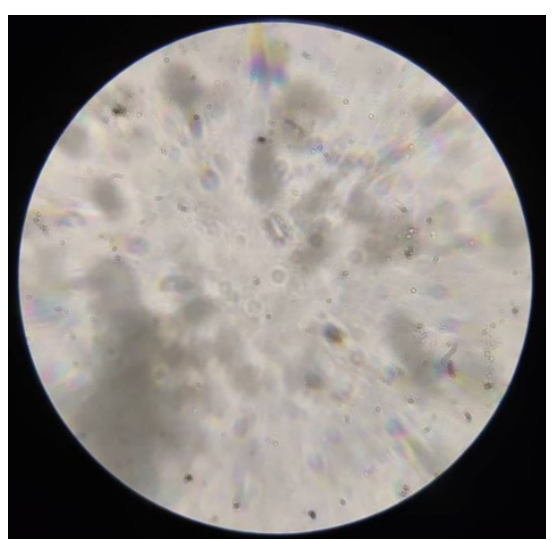

Gambar 2. Mikroskopis simplisia rimpang jahe

Tahap awal formulasi dimulai dengan preformulasi yang dilakukan pada penelitian ini adalah uji kelarutan ekstrak. Uji kelarutan ekstrak dilakukan terhadap beberapa pelarut yang digunakan dalam formulasi yaitu, akuades, etanol $70 \%$, propilenglikol, dan gliserin. Hasil yang diperoleh disajikan dalam Tabel 6. 
Tabel 6. Hasil uji kelarutan ekstrak kering rimpang jahe

\begin{tabular}{ccc}
\hline No & Pelarut & Kelarutan \\
\hline $\mathbf{1}$ & Akuades & 1 bagian ekstrak larut dalam 100 bagian pelarut \\
$\mathbf{2}$ & Etanol 70\% & 1 bagian ekstrak larut dalam 100 bagian pelarut \\
$\mathbf{3}$ & Propilenglikol & 1 bagian ekstrak larut dalam 200 bagian pelarut \\
$\mathbf{4}$ & Gliserin & 1 bagian ekstrak larut dalam 300 bagian pelarut \\
\hline
\end{tabular}

Formulasi ekstrak kering rimpang jahe yang diperoleh berupa sirup sehingga perlu dilakukan optimasi propilenglikol sebagai kosolven sekaligus anti-caplocking. Hasil optimasi yang diperoleh dari uji evaluasi sediaan yang dilakukan meliputi organoleptis, $\mathrm{pH}$, homogenitas, volume terpindahkan, dan visikositas (Tabel 7-9).

Tabel 7. Organoleptis sediaan sirup ekstrak rimpang jahe

\begin{tabular}{lllc}
\hline Sampel & \multicolumn{1}{c}{ Warna } & Bau & Konsistensi \\
\hline Formula 1 & Kuning-orange & Khas Jahe & Encer \\
Formula 2 & Kuning-orange & Khas Jahe & Encer \\
Formula 3 & Kuning-orange & Khas Jahe & Encer \\
\hline
\end{tabular}

Tabel 8. $\mathrm{pH}$, homogenitas, dan volume terpindahkan sediaan sirup ekstrak rimpang jahe

\begin{tabular}{ccccc}
\hline Sampel & pH & Asam/Basa & Homogenitas & Volume terpindahkan (\%) \\
\hline Formula 1 & 1,85 & Asam & Homogen & $100 \%$ \\
Formula 2 & 1,98 & Asam & Homogen & $99 \%$ \\
Formula 3 & 1,99 & Asam & Homogen & $99 \%$ \\
\hline
\end{tabular}

Viskositas merupakan hal yang sangat penting terhadap tahanan dari suatu cairan atau larutan untuk dapat mengalir.Apabila semakin tinggi nilai viskositas yang diperoleh pada suatu cairan atau larutan, maka akan semakin besar besar pula tahanannya. Seperti cairan sederhana (biasa) dapat diuraikan dalam istilah viskositas absolute. Nilai visikositas dapat ditentukan dengan menggunakan alat viskotester salah satunya adalah viskotester Brookfield. Prinsip dari alat ini adalah menggunakan rotasi yang dikombinasikan dengan setting spindle dan kecepatan putar spindle. Viskositas dan rheologi bertujuan untuk mengukur viskositas cairan Newton dan menentukan jenis aliran nonNewton pada sebuah sampel. Viskositas dengan kata lain merupakan suatu ukuran resistensi dari zat cair atau larutan untuk mengalir. Sedangkan rheologi merupakan suatu ilmu mengenai sifat aliran zat cair atau deformasi zat padat (Rahmatini, 2010).

Pada hasil rheogram yang diperoleh dimana membandingkan kecepetan geser (rpm) dengan Shearing Stress menunjukkan bahwa sediaan sirup ini mengikuti rheogram dari aliran Newton. Viskositas zat aliran newton ditandai dengan meningkatnya rate of share seiring dengan peningkatan kecepatan. Cairan Newton memiliki nilai sharing stress yang sebanding dengan nilai rate of share atau kecepatan geser. Oleh sebab itu, viskositas yang dihasilkan konstan pada suhu dan tekanan tertentu dan tidak tergantung pada kecepatan geser, sehingga nilai viskositasnya hanya ditentukan pada satu kecepatan geser. Ketergantungan suhu dan teori viskositas, bila viskositas gas meningkat dengan meningkatnya suhu, maka viskositas cairan justru menurun jika temperatur dinaikkan (Voight, 1995). 
Tabel 9. Visikositas sediaan sirup ekstrak rimpang jahe fotmula 1

\begin{tabular}{|c|c|c|c|}
\hline \multirow[b]{2}{*}{$\begin{array}{l}\mathrm{dv} / \mathrm{dx} \\
(\mathrm{rpm})\end{array}$} & \multicolumn{3}{|c|}{ Formula 1} \\
\hline & $\begin{array}{c}\text { Torsi } \\
(\%)\end{array}$ & cPs & $\begin{array}{c}\text { Shearing stress } \\
\text { (F/A) }\end{array}$ \\
\hline 30 & 0,7 & 8 & 240 \\
\hline 50 & 2,2 & 17,6 & 880 \\
\hline 100 & 6,6 & 26,4 & 2640 \\
\hline \multirow[b]{2}{*}{$\begin{array}{l}\mathrm{dv} / \mathrm{dx} \\
(\mathrm{rpm})\end{array}$} & \multicolumn{3}{|c|}{ Formula 2} \\
\hline & $\begin{array}{c}\text { Torsi } \\
(\%)\end{array}$ & cPs & $\begin{array}{c}\text { Shearing stress } \\
\text { (F/A) }\end{array}$ \\
\hline 30 & 1,4 & 14,1 & 423 \\
\hline 50 & 4,2 & 27,2 & 1360 \\
\hline 100 & 11,4 & 45,6 & 4560 \\
\hline \multirow[b]{2}{*}{$\begin{array}{l}\mathrm{dv} / \mathrm{dx} \\
(\mathrm{rpm})\end{array}$} & \multicolumn{3}{|c|}{ Formula 3} \\
\hline & $\begin{array}{c}\text { Torsi } \\
(\%)\end{array}$ & cPs & $\begin{array}{c}\text { Shearing stress } \\
\text { (F/A) }\end{array}$ \\
\hline 30 & 2,9 & 24,3 & 229 \\
\hline 50 & 7,5 & 50,7 & 2535 \\
\hline 100 & 22,1 & 88,4 & 8840 \\
\hline
\end{tabular}

Ket: $\mathrm{cPs}=$ viskositas

$\mathrm{dv} / \mathrm{dx}=$ kecepatan geser

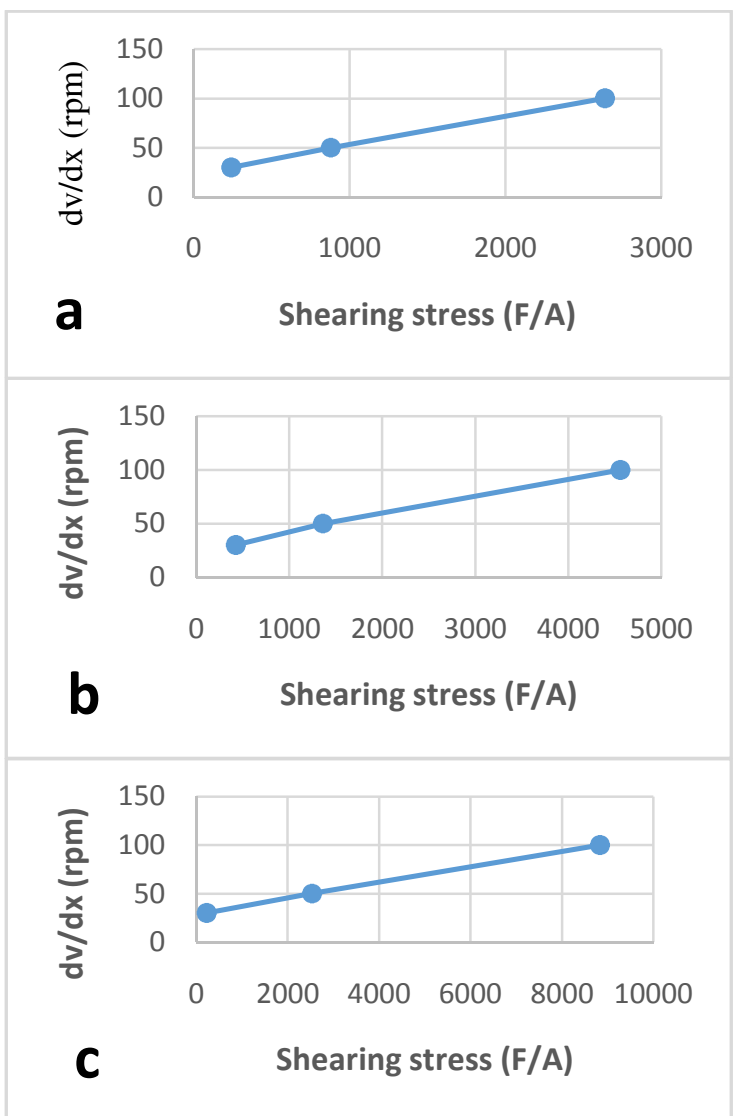

Gambar 3. Rheogram uji visikositas sediaan sirup ekstrak rimpang jahe. (a) rheogram formulasi 1, (b) rheogram formulasi 2, (c) rheogram formulasi 3 .

\section{SIMPULAN}

Dari ketiga formulasi yang digunakan belum memenuhi persyaratan uji fisik, yaitu uji keasaman $(\mathrm{pH})$ dan visikositas. Hal tersebut disebabkan oleh serbuk simplisia yang dibeli tidak terjamin keasliannya. Oleh sebab itu disarankan untuk penelitian lebih lanjut agar memperoleh sampel yang layak uji. Dari ketiga formula yang dilakukan, formula 3 lebih baik daripada formula 1 dan 2 jika dilihat dari hasil uji stabilitas fisiknya.

\section{DAFTAR PUSTAKA}

Ambari, Y. 2018. Uji Stabilitas Fisik Formulasi Elixir Paracetamol Dengan Kombinasi Co-Solvent Propilen Glikol Dan Etanol. Journal of Pharmaceutical Care Anwar Medika. 1(1): 1-6.

Bera, K., Nasalova, G., Sivova, N. and Ray, B. 2016. Structural Elements and Cough Suppressing Activity of Polysaccharides from Zingiber officinale Rhizome. Phytotherapy Research. 30: 105-111.

Endarini, L. H.. 2016. Farmakognosi dan Fitokimia. Jakarta: KemenKes RI.

Harbone, J. B, 1987. Metode Fitokimia, Penuntun Cara Modern Menganalisis Tumbuhan, Edisi Kedua. Penerbit ITB, Bandung, 69-76.

Hernani, Winarti, C. dan Marwati, T. 2009. Pengaruh Pemberian Ekstrak Daun Belimbing Wuluh Terhadap Penurunan Tekanan Darah Pada Hewan Uji. Jurnal Pascapanen. 6(1): 54-61.

Khare, C. P. 2007. Indian Medicinal Plants. New Delhi: Springer Science + Business Media, LCC.

Kritikar K. R, Basu B. D. 2007. Indian Medicinal Plants. Dehradun, India: International Book Distributers. Vol. 4. 2nd ed.

Kumar, G., L. Karthik, K. V., and Rao, B., 2011. A Review on Pharmacological and Phytochemical Properties of Zingiber officinale Roscoe (Zingiberaceae). Journal of Pharmacy Research. 9(4): 2963-2969. 
Optimasi Propilenglikol dalam Sediaan Sirup Obat Batuk Ekstrak Rimpang Jahe (N. P. A. I. Artania, I K. G. G. G. Harta, G. W. A. P. Pratama, N. P. A. S. Ayu, I. G. A. P. Sukmarani dan C. I. S. Arisanti)

Murtini, Gloria. 2016. Farmasetika Dasar. Jakarta: Kementrian Kesehatan Republiki Indonesia.

Rahmatini. 2010. Evaluasi Khasiat dan Keamanan Obat. Majalah Kedokteran Andalas. 34(1).

Ross, I. A. 2005. Medicinal plants of the world.New jersey, USA: Humana press.

Sukarman. 2013. Production and Management of White Big Ginger (Zingiber officinale) Through Seed Industri. Jurnal Litbang Pertanian. 32(2): 76-88.

Uddin, H., Khalid, R. S., Alaama, M. A., Abdualkader, M., Kasmuri, A., and Abbas, S. A. 2016. Comparative study of three digestion methods for elemental analysis in traditional medicine products using atomic absorption spectrometry. Journal of Analytical Science and Technology. 7(6): 1-7. 